\title{
Effect of Heat Treatment on Microstructure and Mechanical Properties of ZM6 Alloy Prepared by Solid Recycling Process
}

Lihua Wen, Zesheng Ji, Xiaoliang Li, and Mingde Xin

\author{
(Submitted July 28, 2008; in revised form October 9, 2008)
}

\begin{abstract}
ZM6 magnesium alloy was prepared by solid recycling process. Effect of heat treatment on microstructure and mechanical properties of the alloy was investigated. Cold pressing was employed to prepare extrusion billets of ZM6 chips, then the billets were hot extruded at $773 \mathrm{~K}$ with an extrusion ratio of 25:1. During hot extrusion, the grains refined and the particles were broken. The peak-aging materials showed fine plateshaped $\beta^{\prime}$ precipitates. The ultimate tensile strength and elongation to failure of as-extruded rods was 232.2 MPa and 23\%, respectively. After $\mathrm{T} 5$ and $\mathrm{T} 6$ heat-treatment, obvious improvement of the tensile strength was obtained because of dispersive particles or fine precipitates. The morphology of the fracture surfaces was examined by employing scanning electron microscope.
\end{abstract} $\begin{array}{ll}\text { Keywords } & \begin{array}{l}\text { Hot extrusion, Mechanical properties, Microstructure, } \\ \text { ZM6 alloy }\end{array}\end{array}$

\section{Introduction}

Magnesium is one of the lightest metals and an abundant element that constitutes about $2.3 \%$ of earth's crust. There are many distinguished properties such as high specific strength, specific stiffness, and good electromagnetic shielding characteristics (Ref 1) of magnesium alloys for use in automobile; aerospace and $3 \mathrm{C}$ industries. It is easily recyclable and considered as green and environmental protection material in the 21 st century (Ref 2). On the other hand, because of resource depletion in the future, recycling of materials draws more and more attention in order to ensure the sustainable development of society. In general, metallic scraps always can be remelted to be cast into ingot for subsequent processing. However, this liquid state recycling may not be efficient for magnesium alloys because of the needs of special protective environment and extra caution. Hot extrusion is an advanced technique for recycling magnesium machined chips because it is not expensive, and extruded materials show excellent mechanical properties (Ref 3, 4).

Many studies showed that magnesium alloys such as AZ31 (Ref 5), ZK60 (Ref 6), and AZ91 (Ref 7) prepared by solid recycling process exhibited high tensile strength and high elongation to failure. In this article, cold-pressing was employed to prepare extrusion billets of ZM6 magnesium alloy chips. Hot extrusion was carried out at $773 \mathrm{~K}$. Extrusion

Lihua Wen, Zesheng Ji, Xiaoliang Li, and Mingde Xin, School of Materials Science and Engineering, Harbin University of Science and Technology, 4 Linyuan Road, Harbin 150040, China. Contact e-mail: jmswlh2000@yahoo.com.cn. ratio is 25:1. Effect of heat treatment on microstructure and mechanical properties of ZM6 magnesium alloys prepared by solid recycling process is discussed.

\section{Experimental Procedures}

The chemical composition of the ZM6 alloy is Mg3.0wt.\%Nd-0.4wt.\%Zn-0.4wt.\%Zr. The alloy chips were prepared by machining an as-received ingot in a lathe. The appearance of machined chips is shown in Fig. 1. The size of a chip was 4-5 $\mathrm{mm}$ in length, $1.5-2 \mathrm{~mm}$ in width, and $0.5 \mathrm{~mm}$ in thickness. The machined chips were filled into a cylindrical container with a diameter of $40 \mathrm{~mm}$ and cold pressed by slowly increasing pressure up to $300 \mathrm{MPa}$ for $30 \mathrm{~s}$ at room temperature into billets. Then the billets were hot extruded into rods. The extrusion temperature was $773 \mathrm{~K}$ with a speed of about $0.15 \mathrm{~mm} / \mathrm{s}$. The diameter of as-extruded rod was $8 \mathrm{~mm}$ with extrusion ratio of 25:1. Some of extruded specimens were solution treated at $803 \mathrm{~K}$ for $2.5 \mathrm{~h}$ in an electric resistance furnace under the mixed atmosphere of $\mathrm{SO}_{2}$ and $\mathrm{SF}_{6}$ with the ratio of 100:1, quenched into hot water at $\sim 333 \mathrm{~K}$ (extrudedT4), and then subsequently aged at $473 \mathrm{~K}$ (extruded-T6). A few of the extruded specimens were directly aged at $473 \mathrm{~K}$ for $16 \mathrm{~h}$ (extruded-T5).

Tensile experiments were performed at room temperature at a strain rate of $5 \times 10^{-3} \mathrm{~s}^{-1}$ on WDW-10 electron universal strength testing machine. The samples were machined into tensile specimens of 5-mm gauge diameter and 25-mm gauge length. The tensile axis was parallel to the extrusion direction. The ultimate tensile stress, $0.2 \%$ offset yield stress, and elongation to failure were recorded. Each datum was the average of results from more than three samples. Specimens were etched in $4 \%$ nitric acid liquor for microstructure observation. Microstructures were examined by using OLYMPUS-GX71-6230A optical microscope $(\mathrm{OM})$ and transmission electron microscope (TEM, Philips CM20 and JEM-2010) operating at $200 \mathrm{kV}$. 
A FEI-SIRION scanning electron microscope (SEM) was employed for the observation of the fracture surfaces of the specimens.

\section{Results and Discussion}

\subsection{Effect of Aging Time}

The extruded specimens from the consolidated chips were solution treated at $803 \mathrm{~K}$ for $2.5 \mathrm{~h}$, and then aged at temperature of $473 \mathrm{~K}$ for various periods of time. The variation in tensile strength with aging time plotted as the aging curve is given in Fig. 2. It takes about $16 \mathrm{~h}$ to reach peak aging. The peak-aged specimen presents an ultimate strength of 294.5 MPa with an elongation to failure of $13.5 \%$. After $16 \mathrm{~h}$ aging, the alloy suffers an obvious overaging with the decrease in tensile strength from 294.5 to $252.1 \mathrm{MPa}$.

Figure 3 shows the evolution of the aging microstructure on the plane perpendicular to the extrusion direction. As the aging process reaches the time of $16 \mathrm{~h}$, a large amount of the second phase particles precipitate homogeneously from the $\alpha-\mathrm{Mg}$ matrix. The average grain size was $25.3 \mu \mathrm{m}$. The solution and aging treatment results in a more homogeneous distribution of

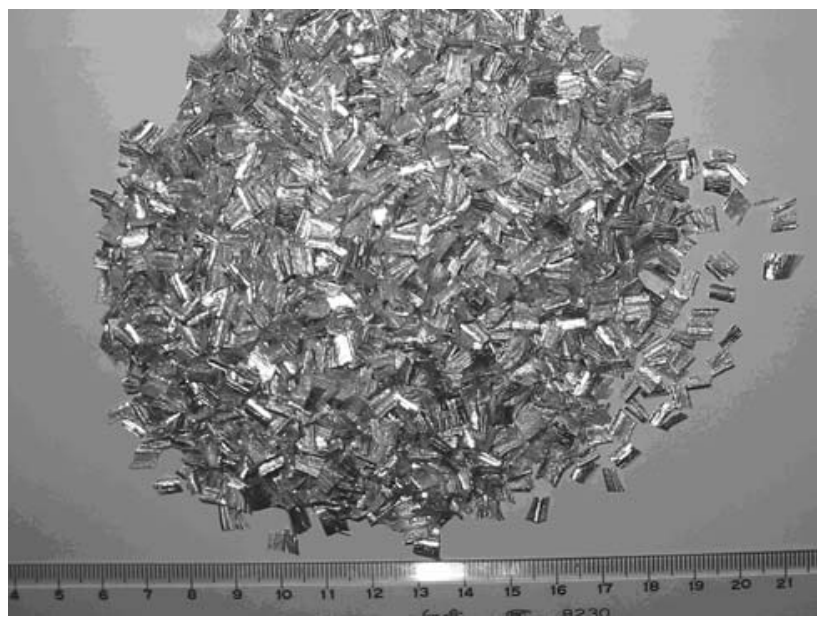

Fig. 1 Machined chips of the alloy

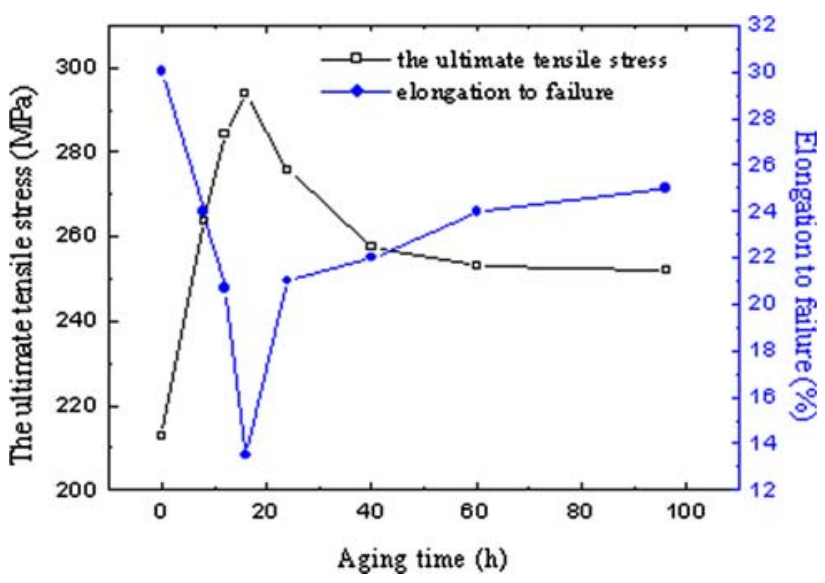

Fig. 2 The variation with aging time of the tensile properties the microprecipitates throughout the entire volume of the ZM6 alloy. The particles of the specimen aged for $96 \mathrm{~h}$ are much bigger than that of the specimens aged for $16 \mathrm{~h}$. Figure 4 presents transmission electron micrographs recorded from an alloy sample aged at $473 \mathrm{~K}$ for $8 \mathrm{~h}$, with the incident electron beam approximately parallel to $[0001]_{\alpha}$. Many shaft-like precipitates were formed and distributed in the matrix, as shown in Fig. 4(a). In the corresponding selected area electron diffraction (SAED) pattern (Fig. 4b), there was a hexagonal
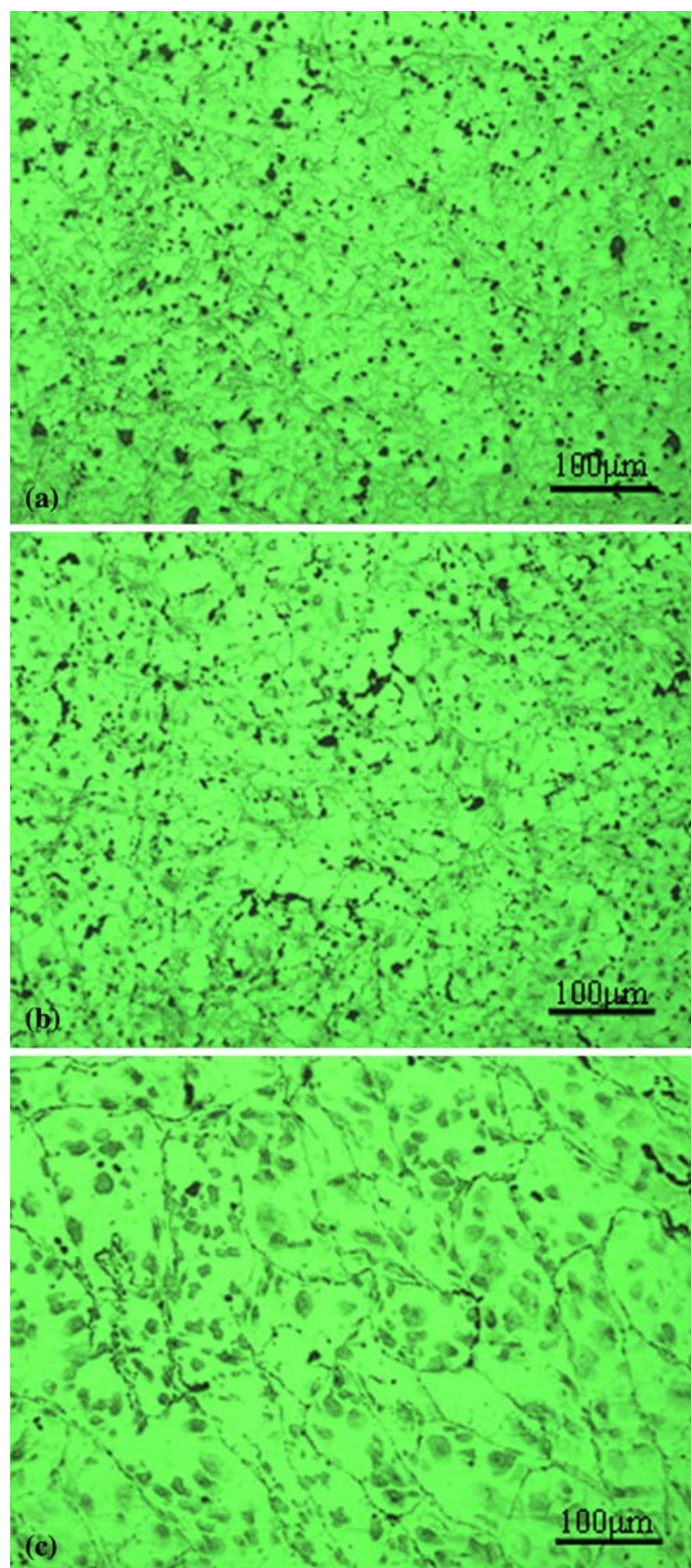

Fig. 3 Optical microstructures of the rods aged at $473 \mathrm{~K}$ for various aging time. (a) $12 \mathrm{~h}$; (b) $16 \mathrm{~h}$; (c) $96 \mathrm{~h}$ 

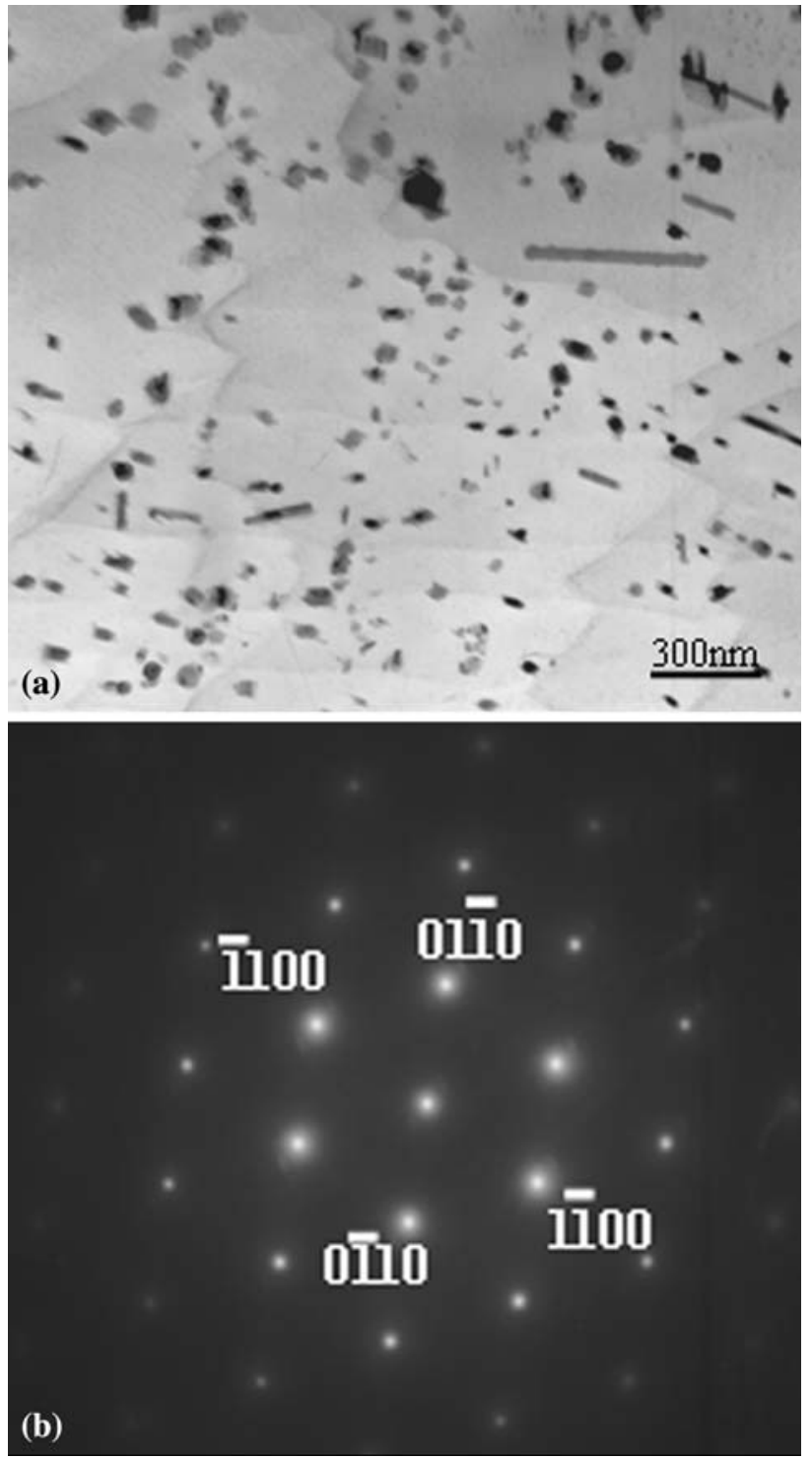

Fig. 4 Transmission electron micrographs recorded from an alloy sample aged at $473 \mathrm{~K}$ for $8 \mathrm{~h}$. (a) Bright-field images; (b) SAED patters taken along $[0001]_{\alpha}$

D0 19 structure in the alloys, namely $\beta^{\prime \prime}(\operatorname{Ref} 8)$. At the peakand over-aged stages, plate-shaped precipitates were observed. Figure 5(a) and (b) shows bright field images recorded from the alloy samples aged at $473 \mathrm{~K}$ for 16 and $96 \mathrm{~h}$, respectively. From the aging time of 16-96 h, the plate-shaped precipitates grew from typical $\sim 200 \mathrm{~nm}$ in length, with a thickness of $<10$ to $\sim 400 \mathrm{~nm}$ in length, with a thickness of $\sim 10 \mathrm{~nm}$. The SAED pattern corresponding to Fig. 5(a) was face-centered cubic structure, namely $\beta^{\prime}$. The plate-shaped $\beta^{\prime}$ precipitates make the strength to be the maximum (Ref 9).

\subsection{Microstructure in Different Conditions}

Figure 6(a)-(c) shows the microstructures of the alloy in the as-extruded, extruded-T4, and extruded-T5, respectively. The extruded specimens exhibited partial dynamic recrystallization and the grains refined greatly. It can be seen from Fig. 6(a) that some coarse brittle intermetallic phases were broken into small particles and moved from grain boundaries to grain interiors
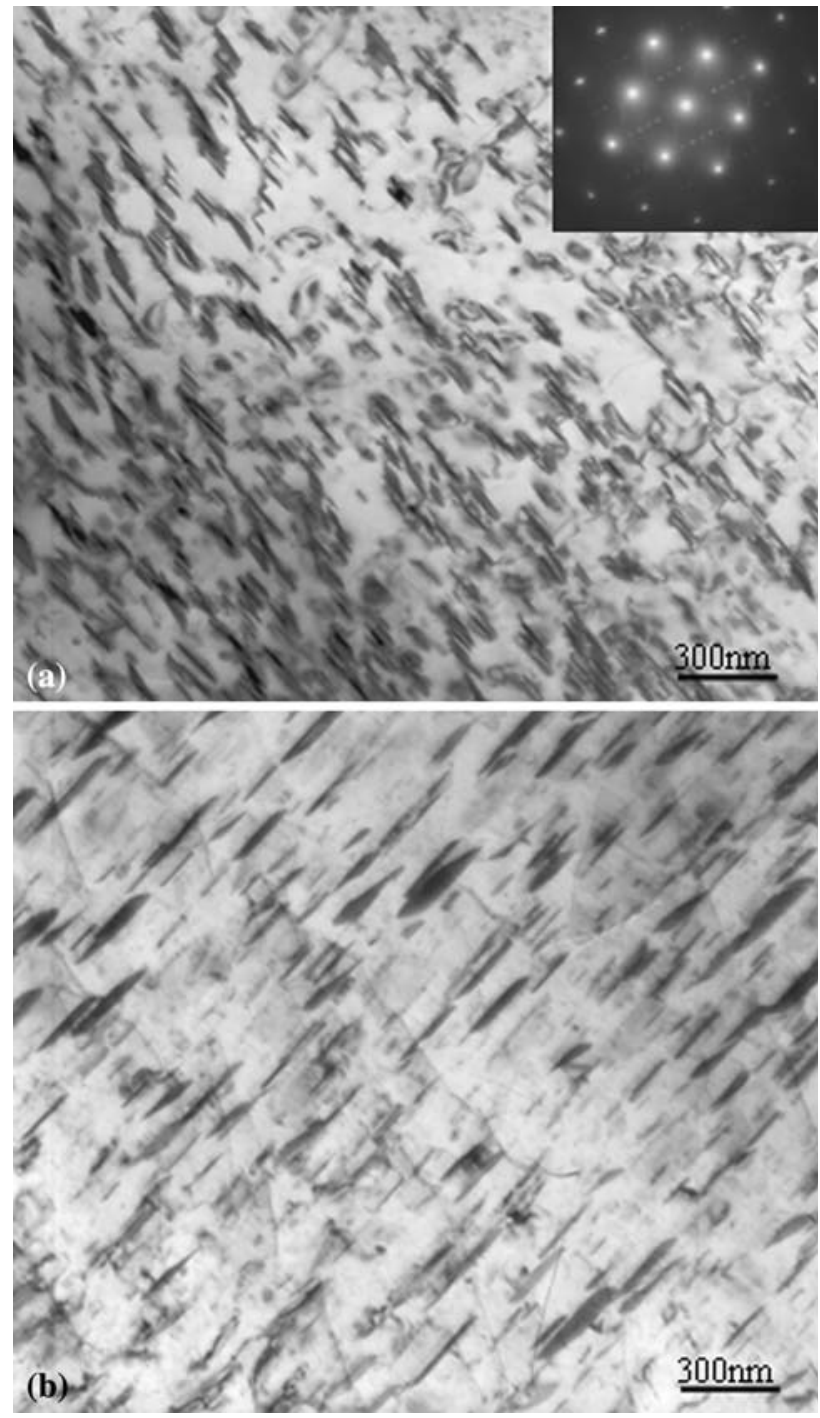

Fig. 5 Bright field images recorded from the samples aged at $473 \mathrm{~K}$ for (a) $16 \mathrm{~h}$ and (b) $96 \mathrm{~h}$

during the hot extrusion process (Ref 10). The solution heat treatment of the alloy at $803 \mathrm{~K}$ for $2.5 \mathrm{~h}$ reduced the Nd-rich second phases at grain boundaries and left only some discrete, rounded precipitates, as shown in Fig. 6(b). This kind of discontinuous particle morphology can improve the ductility of the alloy by reducing the nucleation, growth, and coalescence of cracks and cavities at grain boundaries (Ref 11). In the extruded-T5 condition, the average grain size was $12.3 \mu \mathrm{m}$. The grain refinement and less grain growth tendency may be attributed to the $\mathrm{Mg}_{12} \mathrm{Nd}$ particles which pin the grain boundaries and impede grain growth during extruding and subsequent heat treatment (Ref 12).

\subsection{Mechanical Properties of the Alloy}

Figure 7 presents the mechanical properties at room temperature of the alloy in different conditions. The as-extruded rods have the UTS of $232.2 \mathrm{MPa}$, the TYS of $118.8 \mathrm{MPa}$, and the elongation of $23 \%$. After solution treatment (extruded-T4), the UTS and the TYS have a little decline, but the elongation increases from 23 to $30 \%$. Compared with those of the 


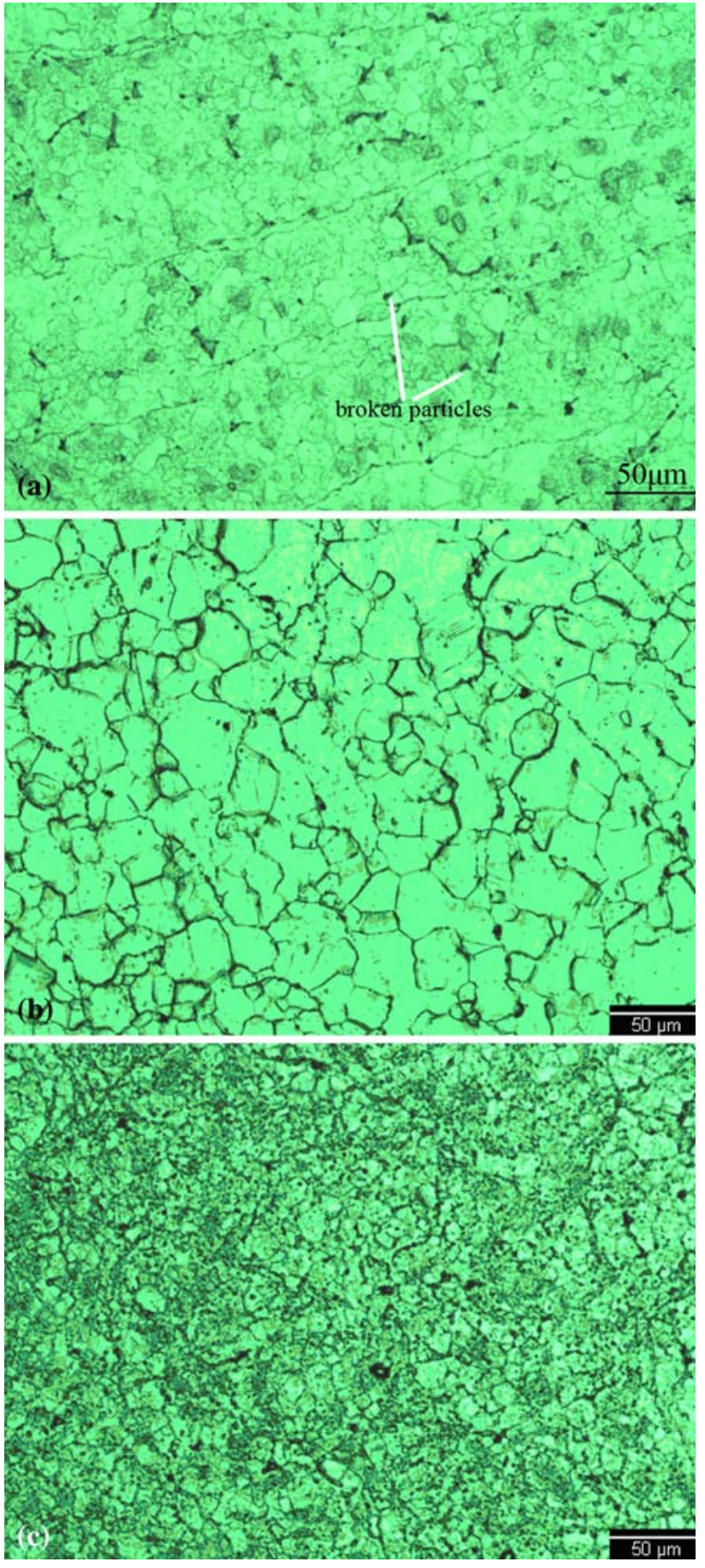

Fig. 6 Microstructures of the samples in different conditions. (a) As-extruded; (b) extruded-T4; (c) extruded-T5

as-extruded rods, both the UTS, and the TYS of the extrudedT5 rods increase while the elongation decreases due to the precipitation hardening. Large improvements of the UTS and the TYS are obtained from extruded-T4 condition to extrudedT6 condition, but the elongation is greatly reduced. The extruded-T6 rods have the highest UTS of 294.5 MPa and the highest TYS of $142.9 \mathrm{MPa}$.

During the hot-extrusion process, $\mathrm{Mg}_{12} \mathrm{Nd}$ intermetallics were destroyed and broken into small particles, responsible for a substantial strengthening. Furthermore, hot extrusion may

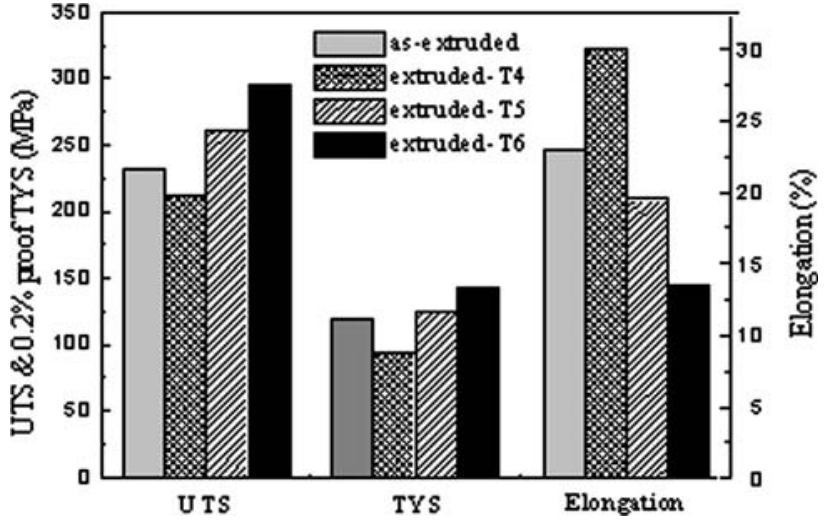

Fig. 7 Mechanical properties at room temperature of the alloy in different conditions

promote the formation of finer microstructure. According to the well-known Hall-Petch relation, the increase in yield stress depends on the grain size as follows (Ref 13):

$$
\Delta \sigma_{0.2}=K d^{-1 / 2}
$$

where $\Delta \sigma_{0.2}$ is the increase in yield stress due to grain refinement, $K$ is a constant, and $d$ is the grain size. In the extruded-T4 condition, many of the particles were resolved into the matrix, which contribute to the tensile strength decreasing and the elongation increasing. In the extruded-T5 condition, the other potential sources of strengthening are the $\mathrm{Mg}_{12} \mathrm{Nd}$ particles, which are observed to exist as relatively small particles. After solution heat treatment and aging treatment, the second phase particles precipitate from the matrix and retard the dislocation movement and grain boundaries migration, producing strengthening effects (Ref 14). In addition, due to the uncoordinated deformation with the matrix, the precipitates may act as crack sources and in turn decrease the elongation to fracture of tensile samples.

\subsection{Fracture Behavior}

Figure 8(a) and (b) shows SEM images of the tensile fracture surfaces of the alloys in the as-extruded and extrudedT6 conditions. It can be seen from Fig. 8(a) that the failure surfaces are composed of some deep and small dimples. The diameter of dimples is about $8-15 \mu \mathrm{m}$. Moreover, apparently tearing ridges are observed in the fracture surface of the as-extruded alloys. Cleavage planes, some dimples and tear ridges are observed in the failure surfaces of the extruded-T6. The cleavage planes means that the direction of the cracks frequently changes during propagation and the crack extension resistance increases. Many small particles are seen in the dimples. The particles are Nd-containing intermetallics by EDS analysis as shown in Fig. 9. Due to the fragile characteristic of Nd-containing compounds, the particles were broken during the tensile test (or during extrusion) and become a cracking source.

\section{Conclusions}

(1) Solid recycling process were carried out on the ZM6 alloy. The solid recycling process consisted of cold 

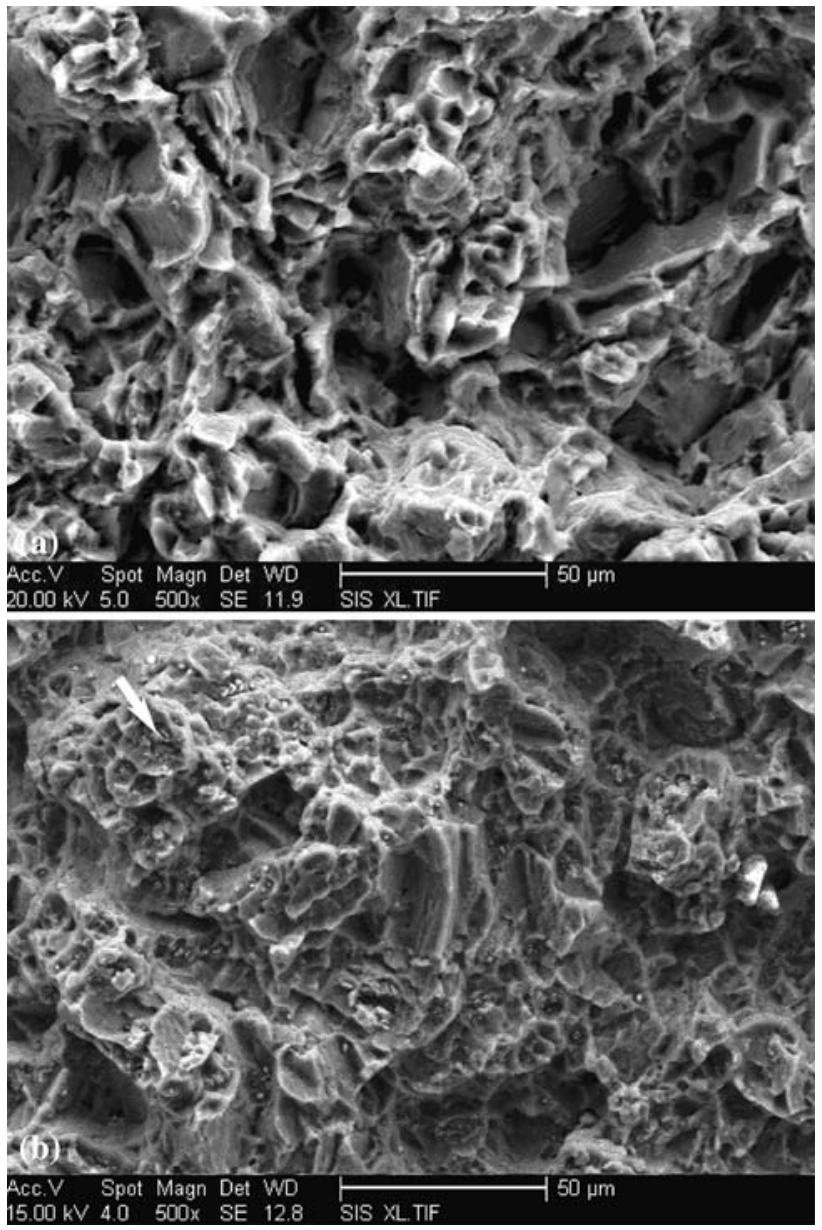

Fig. 8 SEM images of the tensile fracture surfaces. (a) As-extruded; (b) extruded-T6

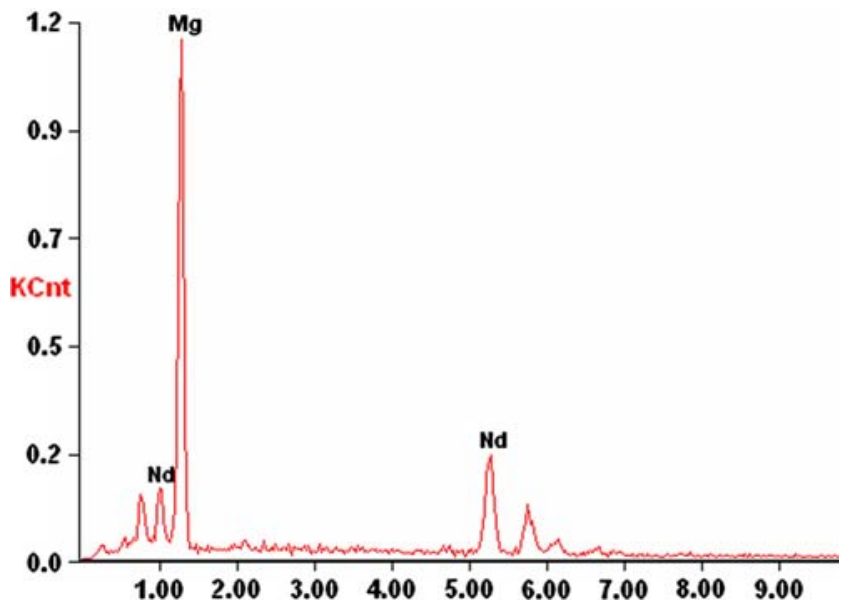

Fig. 9 EDS analysis of arrow site in Fig. 8

pressing of extrusion billets of ZM6 chips and hot extrusion of the billets at $773 \mathrm{~K}$ with an extrusion ratio of $25: 1$.
(2) Grains of the as-extruded specimens were refined because of the occurrence of partial recrystallization. A large amount of the second phase particles were observed in the extruded-T5 and extruded-T6 alloys.

(3) The ultimate tensile strength and elongation of the as-extruded rods was $232.2 \mathrm{MPa}$ and $23 \%$, respectively. After T5 and T6 heat treatment, obvious improvement of the tensile strength was obtained.

(4) SEM observations of the fracture surfaces revealed that the fracture mode of the alloy in the as-extruded and extruded-T6 conditions is a mix mechanism with brittle fracture and gliding fracture.

\section{Acknowledgment}

The authors gratefully acknowledge the financial support by the Chinese National Science Foundation (No. 50674038E0410).

\section{References}

1. H. Li, E. Hsu, J. Szpunar, R. Verma, and J.T. Carter, Determination of Active Slip/Twinning Modes in AZ31 Mg Alloy Near Room Temperature, Mater. Eng. Perform., 2007, 16, p 321-326

2. Z.H. Xiao, J.R. Luo, S.S. Wu, D.N. Li, Y.W. Mao, and X.J. Song, Study on a Semi-Solid Rheo-Diecasting Process with AZ91D Alloy Slurry, Mater. Eng. Perform., 2004, 13, p 60-63

3. H.T. Gao, G.H. Wu, W.J. Ding, and Y.P. Zhu, Recying of Magnesium Alloy AZ91 Scrap by a $\mathrm{B}_{2} \mathrm{O}_{3}$-Containing Flux, J. Mater. Sci., 2004, 39, p 6449-6456

4. S.-H. Hsiang and J.-L. Kuo, An Investigation on the Hot Extrudion Process of Magnesium Alloy Sheet, J. Mater. Process. Technol., 2003, 140, p 6-12

5. H. Watanabe, K. Moriwaki, T. Mukai, K. Ishikawa, M. Kohzu, and K. Higashi, Consolidation of Machined Magnesium Alloy Chips by Hot Extrusion Utilizing Superplastic Flow, J. Mater. Sci., 2001, 36, p 5007-5011

6. M. Nakanishi, M. Mabuchi, N. Saito, M. Nakamura, and K. Higashi, Tensile Properties of the ZK60 Magnesium Alloy Produced by Hot Extrusion of Machined Chip, J. Mater. Sci. Lett., 1998, 17, p 2003-2005

7. J.-Y. Wang, Y.-N. Lin, T.-C. Chang, and S. Lee, Recycling the Magnesium Alloy AZ91D in Solid State, Mater. Trans., 2006, 47, p 1047-1051

8. D.-H. Ping, K. Hono, and J.F. Nie, Atom probe Characterization of Plate-Like Precipitates in a Mg-RE-Zn-Zr Casting Alloy, Scripta Mater, 2003, 48, p 1017-1022

9. S.M. He, X.Q. Zeng, L.M. Peng, X. Gao, J.F. Nie, and W.J. Ding, Microstructure and Strengthening Mechanism of High Strength Mg-10Gd-2Y-0.5Zr Alloy, J. Alloys Compd., 2007, 427, p 316-323

10. A. Singh, M. Nakamura, M. Watanabe, A. Kato, and A.P. Tsai, Quasicrystal Strengthened Mg-Zn-Y Alloys by Extrusion, Scripta Mater, 2003, 49, p 417-422

11. Y. Zhang, X. Zeng, L. Liu, C. Lu, H. Zhou, Q. Li, and Y. Zhu, Effects of Yttrium on Microstructure and Mechanical Properties of Hot-Extruded Mg-Zn-Y-Zr Alloys, Mater. Sci. Eng. A, 2004, 373, p 320-327

12. G.Y. Yuan, M.P. Liu, W.J. Ding, and A. Inoue, Microstructure and mechanical properties of Mg-Zn-Si-based alloys, Mater. Sci. Eng. A, 2003, 357, p 314-320

13. S.M. He, L.M. Peng, X.Q. Zeng, W.J. Ding, and Y.P. Zhu, Comparison of the Microstructure and Mechanical Properties of a ZK60 Alloy With and Without 1.3 wt.\% Gadolinium Addition, Mater. Sci. Eng. A, 2006, 433, p 175-181

14. Y. Fan, G. Wu, H. Gao, G. Li, and C. Zhai, Influence of Lanthanum on the Microstructure, Mechanical Property and Corrosion Resistance of Magnesium Alloy, J. Mater. Sci., 2006, 41, p 5409-5416 